CUAD. CONTAB. / BOGOTÁ, COLOMBIA, 17 (43): 43-72 / ENERO-JUNIO 2016 / 43

\title{
Historia de la regulación contable financiera en Colombia. El caso de la industria ferroviaria (1870-1920)*
}

doi:10.11144/Javeriana.cc17-43.hrcf

\section{Carlos Orlando Rico-Bonilla}

Profesor tiempo completo, Universidad Santo Tomás.

Magíster en contabilidad y finanzas y contador público,

Universidad Nacional de Colombia.

Correo electrónico: carlosricob@usantotomas.edu.co

* Artículo derivado del proyecto de investigación de la Tesis de Maestría en Contabilidad y Finanzas de la Universidad Nacional de Colombia, Historia de la Contabilidad Financiera en Colombia. El caso del Ferrocarril de la Sabana 1880-1915. La Tesis recibió la distinción de Laureada, acorde Resolución No. 034 de 2015 del Consejo Académico de dicha institución. 
Resumen Este documento expone un estudio histórico de la regulación contable desarrollada en Colombia, en el período 1870-1920. Específicamente, se toman en consideración las reglas, los agentes económicos y el contexto social relacionado con la industria ferroviaria, una actividad empresarial fundamental en la constitución de las prácticas y el pensamiento sobre la contabilidad financiera contemporánea.

Palabras clave Colombia; historia de la contabilidad; contabilidad financiera; regulación contable; ferrocarriles

Códigos JEL M41, M48, N76

\section{History of Financial Accounting} Regulations in Colombia. The Case of the Railroad Industry (1870-1920)

\begin{abstract}
This document presents a historical study of accounting regulations developed in Colombia in the 1870-1920 period. Specifically, we consider the regulations, economic agents, and the context related to the railroad industry, a key business activity for the constitution of contemporary financial accounting practices and thought.
\end{abstract}

Keywords Colombia; history of accounting; financial accounting; accounting regulations; railroads

\section{História da regulamentação contábil financeira na Colômbia. O caso da indústria ferroviária (1870-1920)}

\footnotetext{
Resumo Este documento expõe um estudo histórico da regulamentação contábil desenvolvida na Colômbia, no período 1870-1920. Especificamente, são consideradas as regulamentações, os agentes económicos e o contexto social relacionado com a indústria ferroviária, uma atividade empresarial fundamental na constituição das práticas e o pensamento sobre a contabilidade financeira contemporânea.
}

Palavras-chave Colômbia; história da contabilidade; contabilidade financeira; regulamentação contábil; trens

\section{Introducción}

La primera experiencia ferroviaria de Colombia comenzó con la construcción del Ferrocarril de Panamá, en 1850. La explotación de la línea la realizó la Panama Railroad Company. Este proyecto fue distante de los intereses y la política central; la única preocupación fiscal de los diferentes gobiernos en Bogotá, respecto del proyecto, era cómo distribuir las regalías que se obtenían por este concepto desde Estados Unidos (Correa, 2012; Horna, 2003; Pérez-Ángel, 2008; Safford, 2010).

Posteriormente, en la década de 1870, en la opinión pública y en el gobierno liberal radical, ganó fuerza la idea de que el ferrocarril era el motor tecnológico fundamental que podría sacar al país de su precaria condición económica. Por esto, de allí en adelante, la puesta en marcha de estas mejoras materiales constituyó un elemento constante de los programas estatales (Ospina, 1987; Palacios, 2009).

Entre 1869 y 1872, se adelantó con relativo éxito el Ferrocarril de Bolívar, entre Barranquilla y el municipio de Sabanilla, que tenía por objeto gestionar el transporte de productos de importación y exportación que pasaban por la aduana del incipiente puerto caribeño. En esta misma época, además, se adelantaron labores en el Ferrocarril de Antioquia (Medellín-Puerto Berrío), el Ferrocarril de Cúcuta (CúcutaPuerto Villamizar) y el Ferrocarril del Pacífico (Cali-Buenaventura) (Pachón \& Ramírez, 2006; Rippy, 1977). 
La apuesta más ambiciosa fue, sin lugar a dudas, el Ferrocarril del Norte, cuyo trazado buscaba unir los estados de Cundinamarca, Boyacá y Santander. Sin embargo, este proyecto pronto dejó en evidencia la escasez de capital financiero, técnico y humano que tenía el país. Tampoco era probable obtener recursos en el extranjero, pues la debilidad de las finanzas públicas y el incumplimiento con los créditos externos le mantenían a la nación las puertas cerradas a los préstamos e inversiones de este tipo (Fischer, 2001; Horna, 2003; Junguito, 1997).

A la par, la guerra civil de 1876 [ 9 de julio 1876-25 de mayo de 1877] y varias escaramuzas locales sumergieron el optimismo liberal en un contexto de incertidumbre que se extendió con más fuerza al consolidarse el régimen constitucional de la Regeneración en 1886 (Ospina, 1987). Durante esta etapa de la vida política colombiana, los ferrocarriles y en general las políticas de fomento recibieron más atención, aunque esa atención no se materializó en los avances esperados, debido a los complejos problemas que en materia de política fiscal y monetaria precedieron la catastrófica guerra de los Mil Días entre el 17 de octubre de 1899 y el 21 de noviembre de 1902 (Safford, 2010).

Aparte de los trazados mencionados antes, se trabajó en la construcción de los proyectos del Ferrocarril de la Sabana (1881), Girardot (1881), Santa Marta (1882), La Dorada (1882), Santander (1882), Cartagena (1891) y Tolima (1893). La mayoría presentó resultados insuficientes, que se tradujeron en tramos a medio terminar, falta de interconexiones, deterioro de la infraestructura, contratos y empresas inestables con una fuerte tendencia a los litigios, ineficiencia y despilfarro administrativo. No se produjo en Colombia un sistema ferroviario integrado y unificador sino uno fragmentado, marginal al sistema fluvial de botes y bongos que recorrían parte del Río Magdalena (Ospina, 1987; Pachón \& Ramírez, 2006; Pérez-Ángel, 2008; Rippy, 1977; Safford, 2010).

Esta situación se revirtió un poco durante las primeras décadas del siglo XX, en especial en la administración del General Rafael Reyes (7 de agosto de 1904-27 de julio de 1909), con una política de mayor participación estatal en la administración de las sociedades ferroviarias y la nacionalización de varias líneas que estaban en manos de concesionarios extranjeros. Por esta razón, ese período suele matizarse como una etapa preliminar de crecimiento sostenido de la infraestructura de trenes, sustentada recíprocamente en la expansión del mercado de exportación del café (McGreevey, 1975; Ospina, 1987; Palacios, 2009).

En general, para el período 1870-1915, hubo una complicada implementación de proyectos ferroviarios, en especial para los mayores a 150 kilómetros (Fischer, 2001), con dificultades que van desde la escarpada geografía nacional y las cambiantes condiciones climáticas y de salubridad, hasta la constante falta de capital. Al cerrar esta etapa, los trazados apenas sumaban 1.082 kilómetros, es decir, un promedio de $24 \mathrm{~km}$ por año. Por esto, sin lugar a dudas, las investigaciones sobre la materia han afirmado como esta fue para Colombia una experiencia tardía, limitada y de una moderada incidencia en el crecimiento económico (McGreevey, 1975; Ospina, 1987; Pachón \& Ramírez, 2006; Palacios, 2009; Rippy, 1977; Safford, 2010). 
Teniendo en cuenta esta descripción del contexto, la intención del presente artículo es identificar y revisar la regulación contable de los ferrocarriles colombianos, con énfasis en el análisis de las concesiones (contratos entre la administración y los empresarios nacionales y extranjeros) que sirvieron de marco a las prácticas de elaboración, registro y control de la contabilidad en la industria. Para lograr este objetivo, se estudia igualmente la reglamentación general de las cuentas y las tendencias internacionales al respecto.

Por tanto, el documento está dividido en cuatro partes. En la primera se hace una descripción del entorno de la regulación contable de finales del siglo XIX y principios del XX. En la segunda se analizan los aspectos contables que caracterizaron la legislación neogranadina aplicada a los ferrocarriles. En la tercera parte se contextualiza esta información con las prácticas de reglamentación implementadas en Estados Unidos y Europa occidental, lugares donde estos medios de transporte jugaron un rol fundamental en el desarrollo de la contabilidad moderna (Baskin \& Miranti, 1999; Chandler, 1987, 1996; Rico-Bonilla, 2015b). Finalmente, se formulan algunas conclusiones.

\section{Legislación general de las cuentas neogranadinas}

El escaso desarrollo de las fuerzas productivas y las redes comerciales que caracterizó este país durante el siglo XIX, no permitió que la regulación y las prácticas de contabilidad financiera mostraran una evolución muy dinámica en cuanto a su contenido conceptual y técnico.
No obstante, en aquel tiempo, se fueron gestando cambios que poco a poco cimentaron las bases de un conjunto de instituciones legales y cognitivas en torno al universo de las cuentas de las organizaciones, tanto en el sector privado como en el público (Rico-Bonilla, 2010, 2012, 2015a).

Por ejemplo, a partir del aumento de los negocios de exportación de tabaco y quina, en las décadas de 1850 y 1870, se materializó con más intensidad el uso del método de la partida doble como un esquema más oportuno de generación de información financiera y control material de los recursos, incluso, al modo de un sistema de procesamiento de datos soportado en libros de cuentas y balances. En la contabilidad gubernamental, este tema se venía implementando desde las reformas en la hacienda pública de 1846 (Pulgarín-Giraldo \& Cano, 2000; Rico-Bonilla, 2010).

En las prácticas y hábitos mercantiles, predominaban la utilización de inventarios no recurrentes, las partidas sencillas referentes a mayordomos, administradores y consignatarios y en los casos más estructurados, la apertura de cuentas corrientes en función de los títulos y documentos por pagar y cobrar. Los ciclos de negocio eran de corta duración y tenía preponderancia la responsabilidad ilimitada representada en las sociedades comanditarias, en las que primaban las cifras encaminadas a definir el patrimonio del comerciante, sus inversiones y sus gastos (Ariza, 2001; Ripoll de Lemaitre, 2000; Sierra-González, 2001).

Sin embargo, durante esta época, aspectos clave como el período contable equivalente a un año comercial, la separación entre los pro- 
pietarios del capital y la persona jurídica de sus negocios, la unidad monetaria del peso y la formación del balance general como referencia básica de la situación financiera de una entidad se fueron constituyendo en los parámetros básicos del ejercicio de la contaduría y la teneduría de libros (Ariza, 2001; Ripoll de Lemaitre, 2000; Sierra-González, 2001).

Solo hacia finales del siglo XIX, con el establecimiento y la continuidad de sociedades anónimas como los ferrocarriles, se evidencia una disminución de este enfoque patrimonialista por un esquema que incluye informes de rendimiento, indicadores de gestión, títulos valor y control corporativo por medio del revisor fiscal. Como se ha observado en otros países y se plantea en los siguientes apartados, esto se debía a la singular naturaleza económica de este tipo de actividades empresariales y a la participación del Estado como su financiador y regulador.

\subsection{La codificación de la contabilidad} comercial

Cuando los proyectos ferroviarios empezaron a concretarse hacia 1873, regía en Colombia la constitución federal de $1863^{1}$. Bajo este parámetro institucional correspondía a cada uno de los nueve Estados en que se dividía la nación (Cundinamarca, Panamá, Tolima, Cauca,

1 En el siglo XIX neogranadino, el conflicto político entre fuerzas federalistas y centralistas fue constante. La Constitución de 1863 o Constitución de Rionegro (Estados Unidos de Colombia, 1863) fue el resultado del triunfo de las primeras en la Guerra Civil de 1860-1861 [8 de mayo de 1860-12 de noviembre de 1862]. Bajo estas ideas, la promulgación de las leyes recaía de forma principal en cada uno de los Estados, que tenían autonomía administrativa y jurídica en varias materias, entre ellas, el comercio.
Antioquia, Magdalena, Bolívar, Santander y Boyacá), promulgar las reglamentaciones que consideraran pertinentes para el comercio terrestre y la contabilidad en sus respectivas localidades. El nivel central se reservaba los tópicos de regulación en materia de intercambio exterior, marítimo y costero (Bernal-Gutiérrez, 1991; Cardona-Arteaga, 1987).

No obstante, la legislación que produjeron estas entidades descentralizadas fue muy limitada. La infraestructura jurídica a este nivel era muy precaria ya que no se contaba con personal administrativo suficiente y capacitado; por lo tanto, la mayoría adoptó el Código de Comercio que se había emitido para toda la República en 1853 (Nueva Granada, 1853) y cuyo primer borrador se había escrito en 1843 (Means, 2011).

Así mismo, es de advertir que este primer intento de codificación independiente tenía como referente el documento que sobre este tópico se había publicado en España, en 1829 y que, a su vez, tenía como guía el reglamento francés de 1807 (Anzola, 1926; Bernal-Gutiérrez, 1991; Cardona-Arteaga, 1987; Means, 2011; Sierra-González, 2001). Al comparar, cada uno de los artículos de la legislación local con la española, respecto al tema de la contabilidad, se encuentra que todo lo formulado en el Código de Comercio neogranadino de 1853 fue transcrito de forma textual, salvo el artículo 54, que enunciaba una notable prohibición:

Artículo 54. Los libros de comercio se llevarán en idioma español. El comerciante que los lleve en otro idioma, sea extranjero o dialecto especial de alguna provincia del reino, incurrirá en una multa que no bajará de mil 
reales, ni ascenderá de seis mil; se hará a sus expensas la traducción al idioma español de los asientos del libro que se mande reconocer y compulsar, y se le compelerá por los medios de derecho a que en un término que se le señale transcriba en dicho idioma los libros que hubiere llevado en otro (España, Código de Comercio, 1829).

Es altamente probable que está restricción no se haya tenido en cuenta por el ejecutivo y el congreso neogranadinos, para evitar inconvenientes menores a la llegada de comerciantes y capitales extranjeros, sobre todo porque durante todo el siglo XIX se promovieron las acciones encaminadas a facilitar la inmigración de europeos y estadounidenses al territorio nacional (Horna, 2003).

Entonces, tanto el código español como su réplica colombiana disponían la obligación de llevar como mínimo tres libros principales: el Diario, el Mayor o de Cuentas Corrientes y el de Inventarios. Estos documentos eran la base del Balance General en el que se acumulaban los activos y pasivos del comerciante (Anzola, 1926; González, 1958).

A pesar de señalar la necesidad de generar este informe financiero, los códigos no son muy específicos en cuanto a la reglamentación de su elaboración, estructura y publicación. En el caso particular de Colombia, su uso parece no haber sido muy habitual; de hecho, contemporáneamente se afirma:

La contabilidad en el siglo XIX en Colombia fue por lo general un ejercicio permanente de cuadre de cajas y de cuentas, mensual o trimestral, que no contenía balances genera- les de resultados; es por lo tanto difícil construir series de datos con base a sus balances financieros, por lo menos hasta 1915, y tampoco permiten una rápida evaluación anual del estado de los negocios (Ripoll de Lemaitre, 2000, p. 4).

Por otra parte, este es un buen ejemplo de cómo la legislación mercantil y contable manifiesta en los códigos copiados del exterior, estaba bastante alejada de las prácticas que se sucedían en el día a día de los negocios locales (Means, 2011). Mucha legislación colombiana se modificó en función de las tendencias foráneas y no de las necesidades y avances del comercio interno. Esto se explicaba desde aquel entonces, por las limitaciones del país en el área de la infraestructura jurídica y doctrinal:

Varias veces se ha quejado el Tribunal de lo inadecuado que es el código vigente, el cual no guarda armonía con nuestros usos comerciales, ni con las necesidades de esa industria, ni con el estado de atraso en que nos encontramos bajo diversos aspectos. Se conoce a primera vista que él ha sido tomado de alguna nación adelantada; pero, por eso mismo, no es adecuado a nuestra situación actual (Estado de Antioquia, Tribunal Superior, 1875, p. 24).

En este sentido igualmente, aunque la intención de la legislación española era incluir la contabilidad como un seguro y prueba adicional del comerciante ante posibles querellas judiciales (Bernal-Lloréns, 1998), en el caso colombiano, probablemente dominó una ma- 
nifiesta evasión de la responsabilidad de llevar cuentas, que se justificaba en el carácter reservado de los documentos mercantiles².

Posteriormente, la reglamentación comercial sufrió modificaciones en la época de la Regeneración [1878-1898], el proceso centralizador se dirigió a unificar bajo un solo código local la regulación que a partir de 1886 debía regir para toda la nación. Por medio del artículo 3 la Ley 57 de 1887, se adoptó el código del Estado de Panamá emitido en 1869, que estaba sustentado en el de Chile de 1867 (Anzola, 1926; Bernal-Gutiérrez, 1991; Machado-Rivera, 2006; Means, 2011; Sierra-González, 2001; Uribe, 1907).

Bajo este nuevo esquema, el ajuste más destacado en la legislación sobre las cuentas se produjo en los primeros años del siglo XX con la expedición de la Ley 20 de 1905, que demarcó una influencia notable de la contabilidad pública respecto de la privada. En su artículo 6, se consideraba la posibilidad para toda persona natural y jurídica, de llevar su contabilidad simplificada en un libro de Cuenta y Razón (síntesis del Diario y el Mayor), y seguir los diferentes modelos de papeles oficiales y balance general reseñados en el Decreto 1036 de 1904, sobre la contabilidad de la hacienda nacional.

En fin, en una perspectiva global, para el período de la segunda mitad del siglo XIX y principios del XX, la regulación contable privada

2 Ninguna autoridad judicial o administrativa podía hacer investigación o examen alguno de los libros del comerciante, para verificar que estos se llevarán de acuerdo a lo estipulado. La única salvedad se producía en situaciones de litigio, y en la posible inspección debía estar presente el dueño o gerente de la entidad para verificar que efectivamente la revisión se restringiera únicamente a las transacciones en disputa (Anzola, 1926; Bernal, 1998; González, 1958; Uribe, 1907). se caracterizó por su circunscripción a los requerimientos que en materia de libros exigía el derecho comercial consignado en el código neogranadino de 1853, que poco cambió hacia 1920. Esta legislación recibió influencia de las tendencias españolas y chilenas y, como se mencionó antes, de las prácticas y reglas de la contabilidad estatal, tópico del siguiente apartado.

\subsection{Reglamentación de la contabilidad gubernamental}

En el caso de la contabilidad pública, los intentos de reforma más trascendentales se habían producido en 1846, con la incorporación del método de la partida doble en reemplazo del cargo y data a la elaboración y centralización de las cuentas gubernamentales, así como la necesidad de llevar los libros del Diario y el Mayor.

Este proceso de política pública fue complicado y demorado. Solo hasta 1859 logró actualizarse toda la información financiera oficial, en razón a la escasez de personas diestras en la materia que, adicionalmente, se comprometieran con un trabajo arduo y de regular remuneración (Pulgarín-Giraldo \& Cano, 2000; Rico-Bonilla, 2010).

Lo mismo sucedía con la Oficina General de Cuentas, entidad de control administrativo, encargada de fenecer en primera y segunda instancia las cuentas de todos los ramos de la administración pública. Fue un organismo que, desde su constitución en 1850, se había caracterizado por su falta de personal técnico y presupuesto suficiente, cuando no en una falta de identidad misional y el continuo atraso de sus tareas (Rico-Bonilla, 2010). 
Para la época inicial de la construcción y la explotación de los ferrocarriles, y en especial, para aquellos que se constituyeron en una entidad gubernamental de orden nacional o departamental, el marco general contable que se les aplicaba, era el mismo que regía para todo el Estado; es decir, el Libro 3 del Código Fiscal emitido por medio de la Ley 106 de 1873. Esta regulación se mantuvo constante a lo largo del siglo XIX y principios del XX, a pesar incluso de las modificaciones y complementos introducidos por diferentes decretos.

Esta legislación diferenciaba para la contabilidad y sus procedimientos de soporte, entre la administración pasiva y la activa de hacienda. La primera correspondía a las oficinas ordenadoras del gasto: a las secretarías de Estado, las entidades descentralizadas y los municipios; mientras la segunda, a las instancias gubernamentales dedicadas a la recaudación de los impuestos y las rentas.

El ejercicio contable de la administración pasiva estaba concentrado en la formulación, la ejecución y el registro de los presupuestos; en determinar los recursos que se debían apropiar y surtir desde el Congreso de la República para cumplir los múltiples contratos firmados por el gobierno en desarrollo de su representación, funcionamiento e inversión.

El procedimiento más dispendioso era el de la constitución de las órdenes de pago, en especial cuando se trataba de la solicitud de giros de anticipos; y los más considerables rubros eran los sueldos fijos, pensiones y viáticos de los funcionarios; de la misma forma, eran fundamentales las proyecciones para servir los pesados rubros de créditos internos y externos e indemnizaciones.

Por otra parte, en las oficinas recaudadoras, el enfoque estaba centrado en el control de los recursos. En este sentido, cada línea de ingreso tenía una gestión contable diferenciada que se manifestaba en un conjunto de procedimientos y auxiliares propios del objeto de la entidad. Por ejemplo, los ingresos de la renta de salinas se registraban en el libro de almacén principal, los derivados del servicio de correo en el de movimiento de estampilla y los de la casa de la moneda en el de bienes y efectos nacionales.

La mayoría de los ingresos públicos se concentraba en la renta de aduanas que trataba sobre los gravámenes que se derivaban de las importaciones y exportaciones de diversos bienes y servicios; estos rubros se gestionaban especialmente con los libros auxiliares de caja y de cuentas corrientes. Infortunadamente, esta era también el área más sujeta a errores técnicos y fraudes, en razón a los continuos y complicados cambios en las políticas arancelarias y cambiarias (Rico-Bonilla, 2010).

En fin, la unión contable de las administraciones pasiva y activa se producía en la dirección nacional del ramo de Hacienda por intermedio de la cuenta general del presupuesto y del tesoro. Este era un informe bastante complejo de constituir, en la medida en que al cierre del año económico, que era en el mes de septiembre, no se disponía de toda la información que debían suministrar las diferentes entidades gubernamentales, que por lo demás tampoco tenían mucha claridad en cuanto a la realización de su propio corte y balance de cuentas. 
A pesar de que los datos contables se tenían que controlar de forma mensual y anual, y de que las cuentas se debían finiquitar so pena de procesos disciplinarios, eran comunes los retrasos y las pérdidas de información. En las provincias se permitían contabilidades bajo el método de cargo y data para reducir los costos de funcionarios especializados y materiales de escritorio, pero aun así, en las administraciones de hacienda subalternas y municipales comúnmente se presentaban los mayores cuellos de botella del flujo de documentos. No obstante estas dificultades, debe señalarse que la contabilidad del ramo avanzó en diferentes frentes, como en el de consolidar unos principios: unidad de caja, cuenta y responsabilidad (PulgarínGiraldo \& Cano, 2000; Rico-Bonilla, 2010).

Se puede indicar, además, que ya a principios del siglo XX se había logrado cimentar más sólidamente la necesidad de aplicar en todas las oficinas gubernamentales el método de la partida doble para obtener un balance general de ellas, que reflejara una información complementaria de la gestión y los presupuestos. De modo similar, se logró instituir que estas cifras debían estar soportadas en un proceso integral que terminaba con el finiquito contundente de los registros, documentos y cuentas.

Infortunadamente, para las empresas públicas de ferrocarriles, este proceso no era suficiente. En particular, las actividades de esta industria no eran fácilmente clasificables entre una posición de ordenadores de gasto o recaudadores de ingresos. Por esto, para estas empresas fue una constante, derivada de las imprecisiones jurídicas, definirse entre reglas contables oficiales y privadas. Para estudiar es- tas consideraciones es preciso profundizar en el análisis de la legislación específica de los proyectos ferroviarios y su forma de rendir cuenta y razón.

\section{Las concesiones ferroviarias y su contabilidad}

En principio, los proyectos ferroviarios en Colombia eran planteados por capitalistas locales, en el marco de un contrato de privilegio firmado con el gobierno y aprobado por el Congreso nacional o federal del territorio en el que se ubicaba la obra. Una considerable cantidad de estas concesiones nunca llegó a desarrollarse, ya que no se reunían los recursos suficientes para empezar y avanzar en la construcción de la infraestructura comprometida (Fischer, 2001).

En este sentido, en el siglo XIX, fue corriente que en torno a las líneas férreas colombianas se acumularan una gran cantidad de intereses, en los que paradójicamente el establecimiento y la operación de los trenes quedaban al margen. En varios casos se produjeron fraudes al Estado o tortuosos pleitos judiciales por derechos y responsabilidades mal definidas en los contratos. En no pocas ocasiones, se formaron íntegros carteles de contratistas y especuladores locales y extranjeros enfocados en capturar rentas derivadas de estos procesos (Horna, 2003; Junguito, 1997).

En una primera fase durante la administración liberal radical, estas concesiones se reglamentaron, por medio de la ley 69 de 1871; en ella se establecían las obras civiles (puentes, canales, caminos, ferrocarriles) que se considerarían de utilidad y necesidad pública para cada 
Estado federal o región y, por lo tanto, se favorecerían con ayudas gubernamentales como subsidios, exenciones tributarias y prebendas (Pachón \& Ramírez, 2006).

La más importante era una garantía de interés anual del 7\% sobre el valor del capital invertido en la construcción de la obra, con un tiempo límite de 25 años, que caducaba en caso de que la empresa consiguiera durante 5 años consecutivos utilidades iguales o mayores al mencionado privilegio. La obtención del beneficio estaba condicionada al avance y puesta en servicio de la obra (Ortega, 1920).

Otros incentivos incluían la transferencia a estas empresas de terrenos propiedad de la nación o baldíos, y prerrogativas tributarias a la importación de insumos de construcción, material rodante y de locomoción, que incluían la exoneración de los derechos de aduanas y de peajes fluviales o terrestres.

En una segunda fase, en la época de la Regeneración, se emitió la Ley 104 de 1892, la reglamentación más específica sobre ferrocarriles expedida en Colombia en el siglo XIX y principios del XX. En esta directriz legislativa, se reafirmaban con más detalle los beneficios antes descritos y se sumaban otros (Ortega, 1920; Pachón \& Ramírez, 2006).

Por ejemplo, se otorgaban subvenciones hasta de 10.000 pesos oro por kilómetro construido (después se pasó a 15.000) respaldadas en emisiones de bonos de deuda pública, se planteaba un procedimiento administrativo especial para llevar a cabo la expropiación de los terrenos que fueran necesarios para desarrollar los trazados y sus partes colindantes, y quedaron exentos de prestar servicio militar en tiempos de paz los trabajadores de la concesión (Ortega, 1920).

En esta etapa también, la Ley 61 de 1896 les abrió camino a los extintos estados federales, ahora departamentos, para que invirtieran directamente fondos en la construcción y promoción de ferrocarriles, respaldados en el gobierno central. Esta medida fue crítica ya que las entidades descentralizadas asumieron compromisos altos por los que la mayoría de las veces no podían responder. Luego, trasladaban las pérdidas y los litigios al presupuesto nacional (Mariño-Pinto, 1927; Ortega, 1920; Pachón \& Ramírez, 2006).

Otra notable cantidad de legislación adyacente trataba sobre la seguridad y policía de las vías férreas y el material de locomoción relacionado. La Ley 62 de 1887 buscaba asegurar la delimitación adecuada de los trazados e incitar, en lo posible, a las empresas a que asumieran una posición responsable frente a la prevención y las indemnizaciones por accidentes de tránsito (Mariño-Pinto, 1927; Ortega, 1920).

En términos generales, la regulación se enfocó en el otorgamiento de incentivos económicos que atrajeran fondos que contribuyeran a la financiación de los proyectos ferroviarios. Infortunadamente, como se ha mencionado antes, el Estado colombiano no tuvo cómo sostener y pagar estas subvenciones, por lo que esta promesa derivó más bien en un esquema de concesión demasiado liberalizado que generó poco impacto en el progreso de la infraestructura ferroviaria (Fischer, 2001; Horna, 2003; Junguito, 1997; Ospina, 1987; PérezÁngel, 2008).

Este lamentable escenario descansaba además, en la precaria regulación sobre derecho 
comercial en especial de las sociedades anónimas, en la inefectiva intervención estatal sobre el establecimiento de las tarifas del servicio ferroviario y en los superficiales controles técnicos y administrativos.

Esto a pesar de que en las leyes enunciadas y otras más se presentaban directrices importantes al respecto; finalmente, no se logró consolidar un esquema efectivo de rendición y revelación de cuentas e informes financieros y estadísticos. El resultado fue que quedó al libre albedrío de las concesiones - sobre todo las extranjerasdefinir íntegramente sus asuntos contables. Estas temáticas se examinan enseguida.

\subsection{Planeación, administración y control de los ferrocarriles}

Una dificultad propia de los proyectos ferroviarios internacionales era la proposición de unos presupuestos razonables sobre el valor de las obras. Estas estimaciones eran importantes para determinar las perspectivas de planeación, gestión de recursos y financiación y, por consiguiente, cuando había mucha diferencia entre los ingresos y gastos presupuestados y los reales, la mayoría de las veces esto se traducía en inconvenientes entre los agentes relacionados.

Los intentos por desarrollar ferrocarriles en suelo colombiano no fueron una excepción a esta condición. De hecho, esta era normalmente una primera escala de las discordias entre el Estado y los contratistas. El ejercicio de planear y presupuestar era complicado y costoso en sí mismo, y la inestabilidad política del país y las condiciones geográficas imprimían a los datos un alto nivel de inexactitud inherente:

\begin{abstract}
Debido al prolongado proceso y en cierta forma a la irregularidad de la construcción lo mismo que las fluctuaciones en los valores de la tierra y la moneda colombiana, solo un genio en finanzas podría estimar los costos en la construcción de muchas de estas vías (Rippy, 1977, p. 238).
\end{abstract}

Varios inversionistas privados y el Estado colombiano contrataron estudios extensos, con ingenieros locales y extranjeros, para tener una base económica sobre la cual determinar la toma de decisiones respecto del inicio de una edificación particular. Sin embargo, mientras los mentores de diversos proyectos prometían considerables ahorros en materia de insumos y trazados en contraprestación de ingresos generosos, los resultados de muy pocos ferrocarriles se produjeron de esta forma (Ortega, 1920).

Por ejemplo, en 1873, para el desarrollo preliminar del Ferrocarril del Norte se concertaron los servicios de una comisión inglesa, presidida por el ingeniero William Ridley, encargada de definir un conjunto de trazados y estimar su costo. Para la unión de Bogotá con el río Magdalena se sugirió la ruta del río Carare con un valor estimado de 3,5 millones de libras esterlinas (el modelo y los componentes de este presupuesto se aprecian en la figura 1). Sin embargo, cuando se buscó negociar sobre esta base la construcción en sí, los proponentes con más opciones duplicaban estos gastos. La obra solo comenzó a materializarse 20 años después luego de trasladarse entre varias demandas y proyectos concesionarios (Junguito, 1997; Ortega, 1920; Pérez-Ángel, 2008). 
Las limitaciones en la planeación financiera y técnica de los trazados se trasladaban inmediatamente a los costos de construcción y operación de las obras ferroviarias en marcha. Varios de los insumos de material rodante debían importarse de Reino Unido y Estados Unidos a unos costos muy altos y difíciles de determinar, las mismas locomotoras fueron traídas a costa del esfuerzo de muchas personas y animales de carga (Arias de Greiff, 1986; Pachón \& Ramírez, 2006).

\section{GRAN FERROCARIL DEL NORTE EN COLOMBIA. PRESUPUESTO PARA LA LINEA PRINCIPAL DEL FERROCARRIL. \\ Rio Carare a Bogotá.}

Paralela, un metro. Lonjitud, 332 kilómetros, 325 metros.

\begin{tabular}{|c|c|c|c|}
\hline \multirow{2}{*}{ DESORIPOION. } & \multicolumn{3}{|c|}{ Cosxo Tosaz. } \\
\hline & s. & $\mathrm{Cb}$. & P. \\
\hline 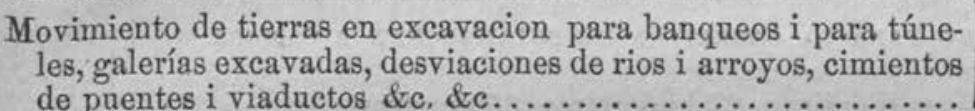 & $1.613,320$ & & \\
\hline 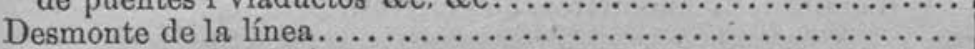 & $\begin{array}{r}1.010,020 \\
9,840\end{array}$ & 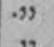 & \\
\hline 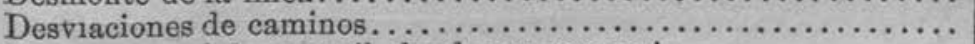 & 5,363 & ", & $"$ \\
\hline Cercas para el ferrocarril, donde sea necesario . . . . . . . . . . . . & 45,197 & $" x$ & $m$ \\
\hline Mampostería en viaductos, puentes, túneles, albañales \&c....... & 440,580 &  & , \\
\hline 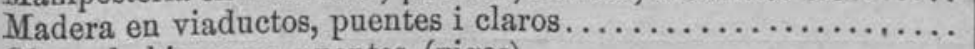 & 304,425 & $"$ & $\pi$ \\
\hline Obras de hierro en puentes (vigas) $\ldots \ldots \ldots \ldots \ldots \ldots \ldots \ldots$ & 4,600 & 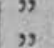 & פ \\
\hline Id. de id. fajas, pernos, \&c. en los viaductos de madera, \&c.... & 61,500 & ") & , \\
\hline Hierro colado para los pilotes (estacadas) $\ldots \ldots \ldots \ldots \ldots \ldots \ldots \ldots$ & 670 & " & " \\
\hline Via permanente en la línea principal i los ladeos.............. & 308,099 & $\eta$ & $\pi$ \\
\hline 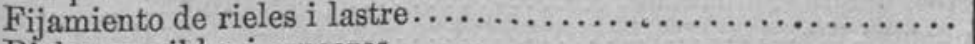 & 92,653 & " & , \\
\hline 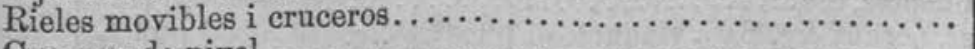 & 1,496 & " & y \\
\hline 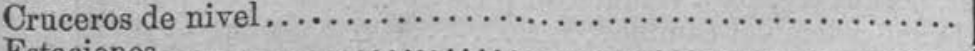 & 639 & " & " \\
\hline 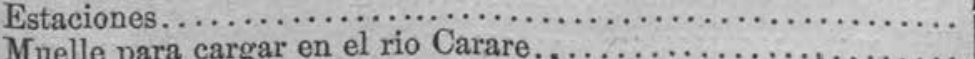 & 19,434 & $"$ & " \\
\hline 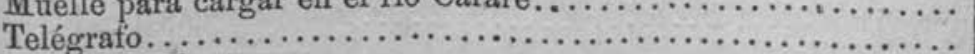 & 11,402 & " & " \\
\hline erial rodante $\ldots \ldots \ldots \ldots \ldots \ldots \ldots$ & 78,720 & " & $2 "$ \\
\hline Tanques de agua, bombas, \&c.............. & 738 & " & 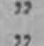 \\
\hline stes de gradiente i miliarios (cada kilómetro) . . . . . . . . . . . . & 246 & " & " \\
\hline Fletes, transportes i aseguros........ & 411,915 & 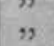 & 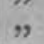 \\
\hline Añádase por gastos imprevistos.... & 121,917 & $"$ & y" \\
\hline Costo total presupuesto para la línea principal. & 33,000 & & \\
\hline
\end{tabular}

17 de setiembre de 1873 .

(Firmado) W: RidLey.

Figura 1

Presupuesto de gastos del Ferrocarril del Norte, trazado de Bogotá al río Magdalena (1874)

Fuente: William Ridley (1874, p. 31) 
La mano de obra no era abundante y mucho menos cualificada en temas de economía industrial. En general, los obreros en el terreno tenían que someterse a unas condiciones de trabajo agobiantes, que en no pocas líneas incluían la exposición a enfermedades tropicales, como la fiebre amarilla (Fischer, 2001). En Colombia, se utilizó poco el trabajo presidiario y no se fomentó la inmigración de los célebres trabajadores chinos, los llamados culies, de hecho se prohibió por medio de la Ley 62 de 1887 (Mejía, 1987; Rippy, 1977).

En esta medida, también era costumbre sobrevalorar los presupuestos de costos. De esta manera, las administraciones ferroviarias podían justificar la obtención de auxilios gubernamentales, en especial de corto plazo (Ortega, 1920). En la figura 2 se muestra un ejemplo del reporte comparativo de presupuesto de gastos, correspondiente al informe de 1901 de la gerencia del Ferrocarril de Cúcuta.

El tema de los presupuestos de las obras es pertinente, porque ilustra un primer eslabón en la cadena de vacíos de regulación sobre los ferrocarriles colombianos. No había una disposición general que instruyera el procedimiento que se debía seguir para planear, administrar y controlar las obras y otorgar estos contratos. Muchas de las posibles propuestas nacían del interés de los inversionistas potenciales por explotar productos agrícolas y minerales de la región aledaña a la futura vía, como en el mencionado caso del Ferrocarril del Norte: café, sal y carbón (Junguito, 1997; Ortega, 1920).

Entonces, al firmar un proyecto ferroviario, luego de formularse un presupuesto de los cos- tos, era necesario establecer una empresa sobre la que recaerían los privilegios y subvenciones mencionadas anteriormente. Sobre la figura societaria que debían adoptar los ferrocarriles, tampoco se implementó ningún parámetro normativo en particular. Como sucedía en otros países de corriente continental europea, las sociedades anónimas que parecían el vehículo de financiación y administración más oportuno para esta industria, no gozaban de una reputación aceptable y, en algunos casos, se optó por entidades comanditarias (Bernal-Gutiérrez, 1991; Means, 2011; Uribe, 1907).

De hecho, el marco reglamentario, consignado en las leyes comerciales y adoptado en toda la nación, establecía:

Artículo 54: Se prohíbe autorizar la fundación de sociedades anónimas contrarias a las buenas costumbres, al orden público, y a las prescripciones de este código; que no versen sobre un objeto real de ilícita negociación, o tiendan al monopolio de la subsistencia o de algún ramo de la industria (Código de Comercio del Estado de Panamá, 1869, p. 66).

A partir del desarrollo de las entidades bancarias, las aseguradoras y los ferrocarriles de finales del siglo XIX se empieza a generar una mayor apreciación del sentido, naturaleza y administración de las sociedades anónimas y de las sociedades de responsabilidad limitada de los socios capitalistas de una organización empresarial (Means, 2011). 


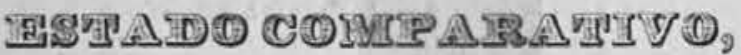

\section{DEL PRESUPUESTO DE GASTOS PARA EL AÑO DE 1000.}

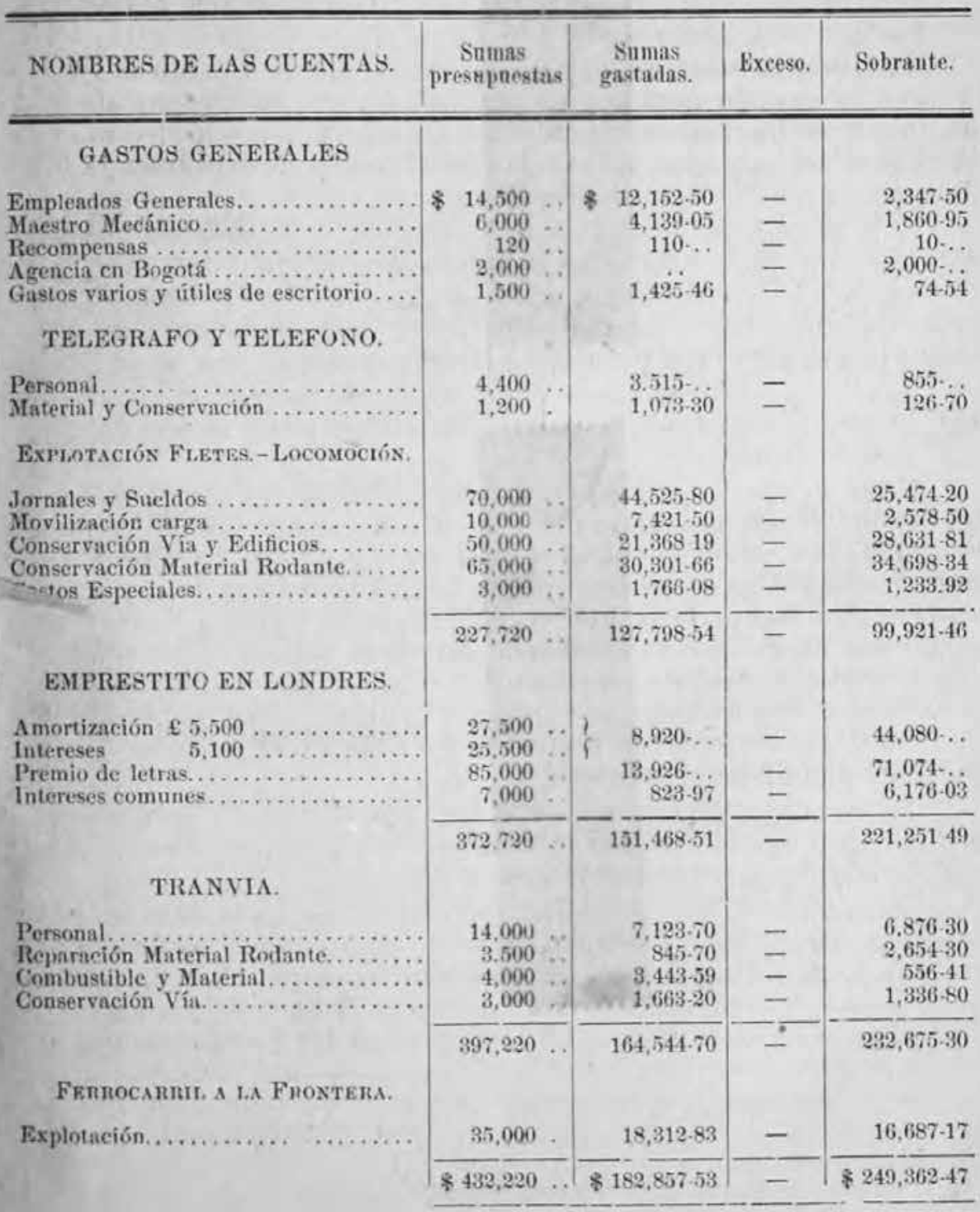

Figura 2

Estado comparativo del presupuesto de gastos del Ferrocarril de Cúcuta (1900)

Fuente: José Agustín Berti (1901, p. 7) 
También en estas industrias se adopta el modelo de administración de asamblea de socios o accionistas, junta directiva y gerencia de la compañía (Means, 2011) y además, se logran estructuras empresariales con cuadros burocráticos definidos en los que se puede identificar una variada cantidad de puestos de trabajo especializado en temas técnicos y administrativos: maquinistas, ingenieros residentes y dibujantes, apuntadores de tiempo, jefes de tráfico, bodegueros y mecánicos de talleres, entre otros.

Pero las limitaciones en materia de regulación se extienden: la Ley 104 de 1892, por ejemplo, habilita a los concesionarios a incurrir en diferentes transacciones comerciales y administrativas (por ejemplo, traspaso de bienes y compra de empresas) pero no facilita unos parámetros conceptuales concretos al respecto, se restringe a anunciar brevemente estas posibles operaciones y cómo deben ajustarse a los principios y obligaciones generales:

(...) Al terminar la época del usufructo, el ferrocarril con todas sus anexidades y dependencias, todo en buen estado de servicio, pasará al dominio del gobierno, sin indemnización a favor del concesionario.

(...) Siempre en caso de compra, el precio fijado se pagará al contado en moneda corriente, y el concesionario tendrá la obligación de entregar la empresa con todas sus anexidades libres de todo gravamen.

(...) El concesionario podrá empeñar la compañía por el tiempo de duración del privilegio.

(...) El contrato podrá traspasarse, previo permiso del Gobierno, cuantas veces quiera el concesionario o quien lo represente, pero en ningún caso a un Gobierno extranjero.
(...) Para la organización de la empresa, el concesionario queda facultado para formar, como lo estime conveniente, la compañía o compañías que a bien tenga, pero siempre sujetas a las leyes colombianas que rijan la materia (Ley 104 de 1892).

Además, cuando se habilitó de una forma más decidida la participación departamental en la contratación y financiación de los ferrocarriles no se hizo claridad en la naturaleza jurídica de posibles empresas de capital mixto, negocios conjuntos o inversiones dominantes. Todo esto derivó en conflictos entre el nivel central y el descentralizado, como sucedió con los Ferrocarriles del Norte, la Sabana y el Sur (Ortega, 1920).

En los casos en que había alguna participación de inversionistas foráneos, se produjeron extensas tensiones políticas con potencias extranjeras como Francia e Inglaterra, ante las cuales el gobierno nacional terminaba cediendo indemnizaciones con tal de no incurrir en conflictos más graves. Esto sucedió, por ejemplo, con el Ferrocarril de Antioquia, el de La Dorada y el de Santa Marta (Fischer, 2001; Horna, 2003; Mariño-Pinto, 1927; Ortega, 1920; Pérez-Ángel, 2008; Safford, 2010).

Como se mencionó antes, las limitaciones jurídicas, en materia de administración y control, se presentaban a pesar de que desde la primera legislación sobre ferrocarriles se facultaba al ejecutivo para intervenir las empresas y determinar los correctivos necesarios para facilitar el mejor desenvolvimiento de la industria ferroviaria y de obras públicas: 
Artículo 6. Será cláusula precisa de los contratos para la concesión de la garantía del gobierno general, que este deba nombrar agentes suyos que inspeccionen la inversión de los fondos en la ejecución de las obras, su dirección, administración y contabilidad, (...) se estipularán expresamente en los contratos los términos de la inspección de los agentes del gobierno, su nombramiento y pago (Ley 69 de 1871).

Con el paso de los años, este requerimiento incluso se reforzó, era una potestad fundamental para que se desarrollara un negocio de vías carrileras que el Estado mantuviera el derecho supremo de inspección, que aplicaba entonces para cualquier sociedad anónima:

Artículo 1. El Gobierno, por graves motivos de necesidad pública, y previo dictamen del Consejo de Ministros, ejercerá en lo sucesivo la suprema inspección sobre todas las compañías anónimas organizadas y radicadas en el país, o que se organicen y radiquen en adelante, a las cuales haya otorgado u otorgue la república subvenciones o auxilios en dinero, tierras baldías, exención de derechos de aduanas u otras concesiones, o que hayan recibido o reciban tierras auxilios semejantes de otras entidades políticas.

Artículo 2. El derecho de inspección consiste en la facultad de examinar, por medio de sus agentes, cuando lo estime necesario el gobierno, los trabajos de dichas compañías, sus libros, cuentas, contratos y demás operaciones y documentos.

Artículo 3. También tendrá derecho el Presidente de intervenir, cuando lo crea necesa- rio, en las elecciones que las juntas generales de accionistas, o las directivas, o las que hagan sus veces (...) esta intervención se extiende a que el gobierno pueda aprobar o desaprobar los nombramientos hechos por tales juntas o asambleas generales para los principales puestos de la empresa respectiva (Ley 27 de 1888).

En este sentido incluso, para 1907, se amplió en la legislación una figura que se venía aplicando muy parcialmente, el modelo de control sustentado en figuras como los comisionados, inspectores y superintendentes. Por medio de la Ley 4 de 1907 se fijó en cabeza del Ministerio de Obras Públicas la gestión y designación de visitas diferenciadas, de carácter técnico, a cargo de ingenieros inspectores y administrativas, a cargo de comisarios inspectores (Mariño, 1927; Ortega, 1920; Uribe, 1907).

Mas la vigilancia que llevaban a cabo estos agentes gubernamentales en materia de contabilidad era limitada, incluso, la directriz por medio de la cual se reglamentan finalmente sus funciones de forma concreta no incluía taxativamente la verificación de las cuentas (Ministerio de Obras Públicas, Resolución 16 de 1920). Se enfocaba más bien en asuntos técnicos como constatar la oportunidad de las rutas y trazados sugeridos, examinar la calidad de los materiales y las edificaciones terminadas y evaluar su sostenimiento y conservación.

Preliminarmente, es posible afirmar que en general en algunas entidades, especialmente aquellas que contaban con participación de inversionistas privados, la supervisión de los temas administrativos recaía en el revisor fis- 
cal. Como sucedía en las entidades bancarias, este funcionario dependía directamente de la asamblea de socios y su encargo era incompatible con cualquier otro empleo en la organización. Su encargo estatutario era el de examinar las cuentas, libros, operaciones de caja y toda la documentación complementaria que le permitiera acreditar la buena marcha de la empresa (Rico-Bonilla, 2012).

Entonces, la escasa e inefectiva aplicación de la regulación sobre presupuestos, figuras societarias y supervisión gubernamental incidió negativamente en la formación de una reglamentación contable particular de la industria y, por ende, se afectó la calidad y utilidad de la información financiera y estadística, como se muestra a continuación.

\subsection{Libros, balances e información financiera}

En Colombia, el esquema de la información financiera de las empresas ferroviarias se enmarcó en las reglas sobre libros y balances que aplicaban al comercio en general, para las entidades privadas. Adicional a los libros básicos de la partida doble para comerciantes (Mayor, Diario, Inventarios y Balances), lo único que de acuerdo con el Código de Comercio debían sumar las empresas de transporte a su contabilidad era una cartilla con la enumeración del dinero, efectos, cofres, valijas y paquetes que condujeran (González, 1958; Uribe, 1907).

Estos documentos se generaban de acuerdo con la discrecionalidad, la responsabilidad y el conocimiento técnico y práctico de las oficinas de contabilidad, que estaban conformadas por contadores, tenedores de libros y auxiliares encargados del registro de las transacciones y su agrupación en reportes (Mejía, 1987).

La mayoría de los ferrocarriles constituyeron también departamentos de estadística, en los que se formulaba un control de los datos de pasajeros, semovientes y mercancías transportadas. Además, se llevaban indicadores de operación, gestión de suministros y materiales y costos (Mayor-Mora, 1984). Estas oficinas — quizás, este es un evento aún por investigar al detalle-fueron las primeras en Colombia en comenzar a darles importancia a la elaboración y la divulgación de reportes sobre el rendimiento o cuentas de resultados, y a equipararlas en relevancia informativa con el balance general y el estado de la caja (Rico-Bonilla, 2015a). En la figura 3 se presenta un ejemplo de este reporte por semestre, aunque también se utilizaba por meses y años.

Sin embargo, la obligación de llevar determinados libros y la publicación que de vez en cuando se hacía de algunos estados financieros, no eran parámetros legales suficientes para solventar el rol básico que debería jugar la reglamentación de la contabilidad ferroviaria como garante del cumplimiento de los contratos entre el Estado y los concesionarios de diferentes líneas y proyectos.

Las Leyes 69 de 1871 y 104 de 1892 avanzaron regularmente en facilitar la intervención gubernamental, mediante la financiación de los proyectos, pero poco hicieron por fortalecer la revelación y la rendición de cuentas que debían prestar las concesionarias por recibir estos cuantiosos y diversos auxilios.

En otras palabras, entre 1870 y 1920 , el gobierno se comprometió con garantías de in- 
terés, subvenciones por kilómetro construido y beneficios tributarios, mas no se preocupó por asegurar una información financiera que resguardara la confianza en el tratamiento y gestión de estos instrumentos por parte de los agentes privados.

Las empresas ferroviarias recibían las ayudas, más por la presión y el cabildeo político de sus propietarios y gestores, que como resultado de un procedimiento legal adecuadamente establecido.

Por ejemplo, ¿cómo podía corroborar el gobierno la necesidad de colaborar con las empresas en el 7\% de los gastos en que incurrían por construcción, si estos se mezclaban con los de operación u otros?, como lo ejemplifica el siguiente comentario de la época:

Las empresas procurarán incluir en el capítulo de gastos de explotación, ciertas partidas que pertenecen más bien a sus gastos en el exterior, o a construcción de obras adicionales, no especificadas en la concesión, o al servicio de su deuda hipotecaria, etc., lo cual se presta a continuas diferencias con el Gobierno, sobre todo si se carece de un buen reglamento de contabilidad (Ortega, 1920, p. 54).

Igualmente, ¿cómo se comprobaba que la compañía no requería los auxilios, porque su utilidad era positiva, si estos datos no eran divulgados y difícilmente se verificaban?

A las empresas les cedían terrenos y otras propiedades inmuebles, incluso después de costosos procesos de expropiación. Pero en ningún momento la administración estatal fijó un método de seguimiento que demostrara la adecuada apropiación y uso de ellos.
La mayoría de concesionarios estaban facultados para emitir bonos y acciones de nombre del ferrocarril con garantía del gobierno nacional, en el populoso mercado de valores de Londres, según la empresa tuviera la solvencia operativa para responder por los intereses de estos títulos. Como no había un control efectivo y una contabilidad regulada, esto daba lugar al oportunismo de estas empresas; entonces, tan pronto corroboraban que no tendrían los flujos de caja para responder a las demandas de los inversionistas extranjeros, los contratistas vendían el proyecto o de inmediato le trasladaban la obligación al Estado (Ortega, 1920; Pérez-Ángel, 2008).

Quizá una de las pocas áreas que tuvo alguna tenue influencia gubernamental en las prácticas de contabilidad de las empresas fue la legislación sobre policía de ferrocarriles. Era obligación cercar la vía férrea con el fin de evitar accidentes (no siempre se cumplía) y había una mayor exigencia en términos de responsabilidad de cara a las contingencias, ya que la costumbre era individualizar y trasladar los peligros y demandas a los empleados (Mariño, 1927; Ortega, 1920; Uribe, 1907). Cuentas como "para imprevistos", “auxilios para accidentes" y "otras provisiones" reflejaban las preocupaciones de los gestores en el manejo de estos riesgos.

Pero ni siquiera la aprobación de la Ley 27 de 1905, que facultaba al poder ejecutivo para comprar e intervenir a su discrecionalidad en las sociedades ferroviarias, logró una modificación de fondo en materia contable. Una década después, en 1915, esta situación se mantenía, si bien en esta época, se reconoció que los ferro- 
HISTORIA DE LA REGULACIÓN CONTABLE FINANCIERA EN COLOMBIA / C. RICO / 61

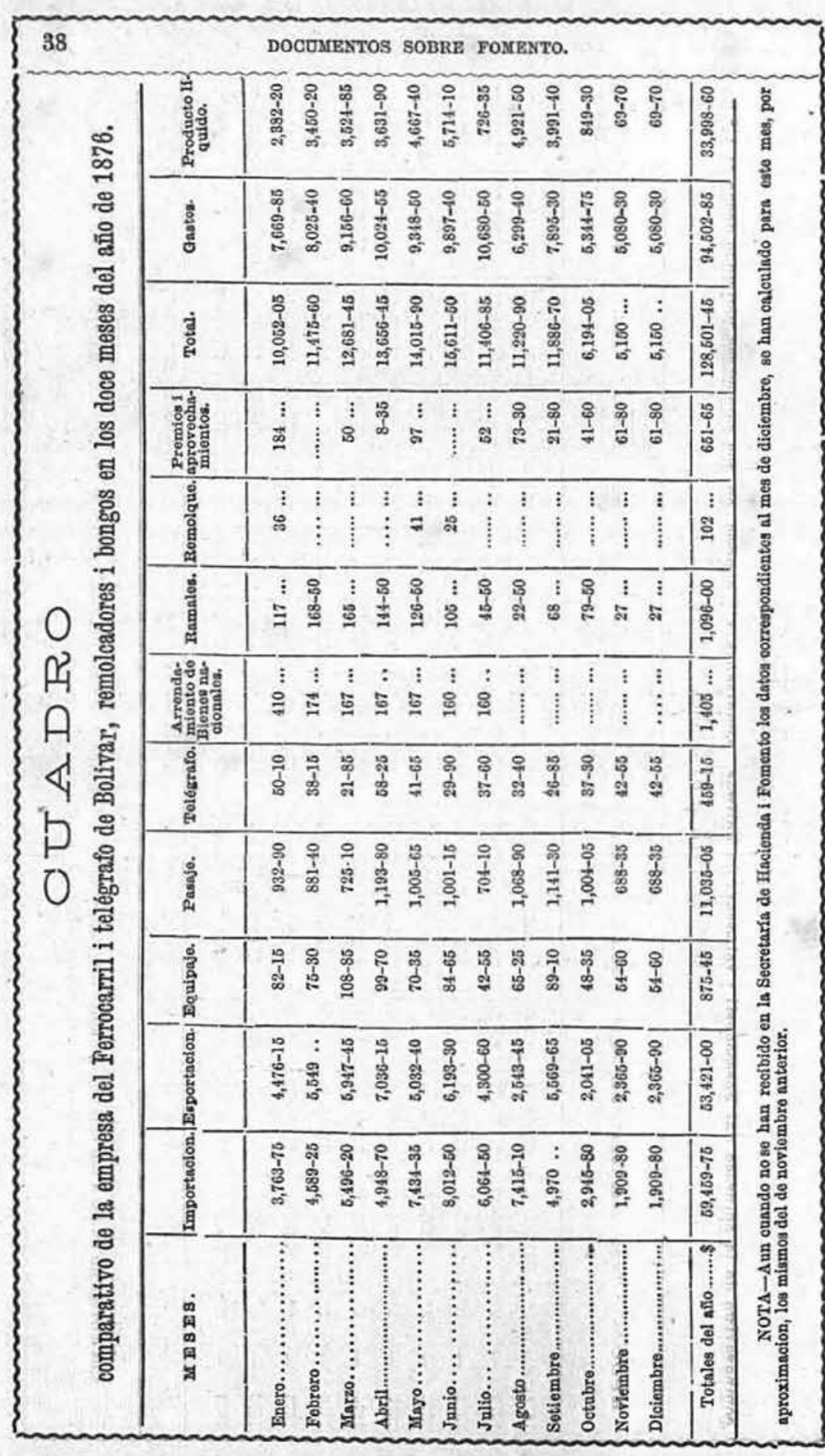

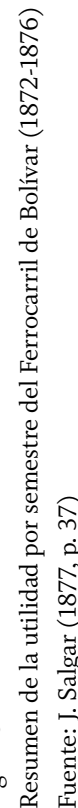


carriles nacionales y departamentales tenían una estructura y una actividad que les imprimía un carácter misional diferente al del resto del Estado. Así, en la industria ferroviaria, apareció el concepto de la empresa de transportes públicos (Mejía, 1987).

Desde entonces, se generó una mayor claridad en cuanto a que la contabilidad que se debía aplicar no era la contenida en el Código Fiscal, pues esta no resultaba adecuada para reflejar la situación económica de los ferrocarriles, sino la que utilizaba el comercio en general, más una regulación específica que debían proporcionar los Ministerios de Obras Públicas y Hacienda:

Artículo 9. No obstante ser bienes nacionales, estarán sujetos los ferrocarriles de que se trata, en su calidad de empresas de transportes públicos, a las disposiciones del Código de Comercio y conforme a este llevarán su contabilidad y correspondencia. Su personería jurídica será representada por el gobierno (Decreto 1115 de 1915).

Está legislación se reglamentó después, en la década de los años veinte, y definió un conjunto de cuentas que el Libro Mayor debía contener e insistió en el uso obligatorio del método de la partida doble. Curiosamente, se afirmaba que la regulación contable que se debía aplicar era la oficial y no la comercial, disyuntiva que — como se ha resaltado- caracterizó la información financiera del sector público:

1. A partir del día $1^{\circ}$ de enero de 1921 , la contabilidad de los ferrocarriles, dependientes del Ministerio de Obras Públicas, será la oficial, por el sistema de partida doble, llevándose los libros prin- cipales que las disposiciones vigentes previenen sobre la materia, y los libros auxiliares que fueren necesarios.

2. Como principales se llevarán en el mayor las siguientes cuentas: capital, explotación, construcción, reconstrucción, caja, almacén, cuentas varias o cuentas corrientes, bancos, gastos generales, material rodante, y las demás que el gerente o contador de la respectiva empresa crea conveniente abrir y que deba llevarse con el carácter de principal (Ministerio de Obras Públicas, Resolución 31 de 1920).

En este contexto general, durante la década de 1910, se dio uno de los pocos — tal vez el único- casos de regulación contable ferroviaria producida por una entidad descentralizada: se trata del Reglamento de la Contabilidad del Ferrocarril de Antioquia, cuya portada se reproduce en la figura 4.

Este documento fue expedido por la Oficina General de Cuentas del departamento y fijaba unas directrices particulares sobre la elaboración de los presupuestos, los libros auxiliares (fletes, caja, almacén, entre otros) que convenía emplear para el registro completo de la información y los soportes que debían obtenerse y conservarse para sustentarlo. Del mismo modo, puntualiza procedimientos para la constitución de inventarios de activos y pasivos, en especial, de las estaciones. Posteriormente, este reglamento fue derogado por uno con un enfoque más comercial, que fue aprobado por la Gobernación de Antioquia y la junta directiva de la empresa (Mayor-Mora, 1984). 
HISTORIA DE LA REGULACIÓN CONTABLE FINANCIERA EN COLOMBIA / C. RICO / 63

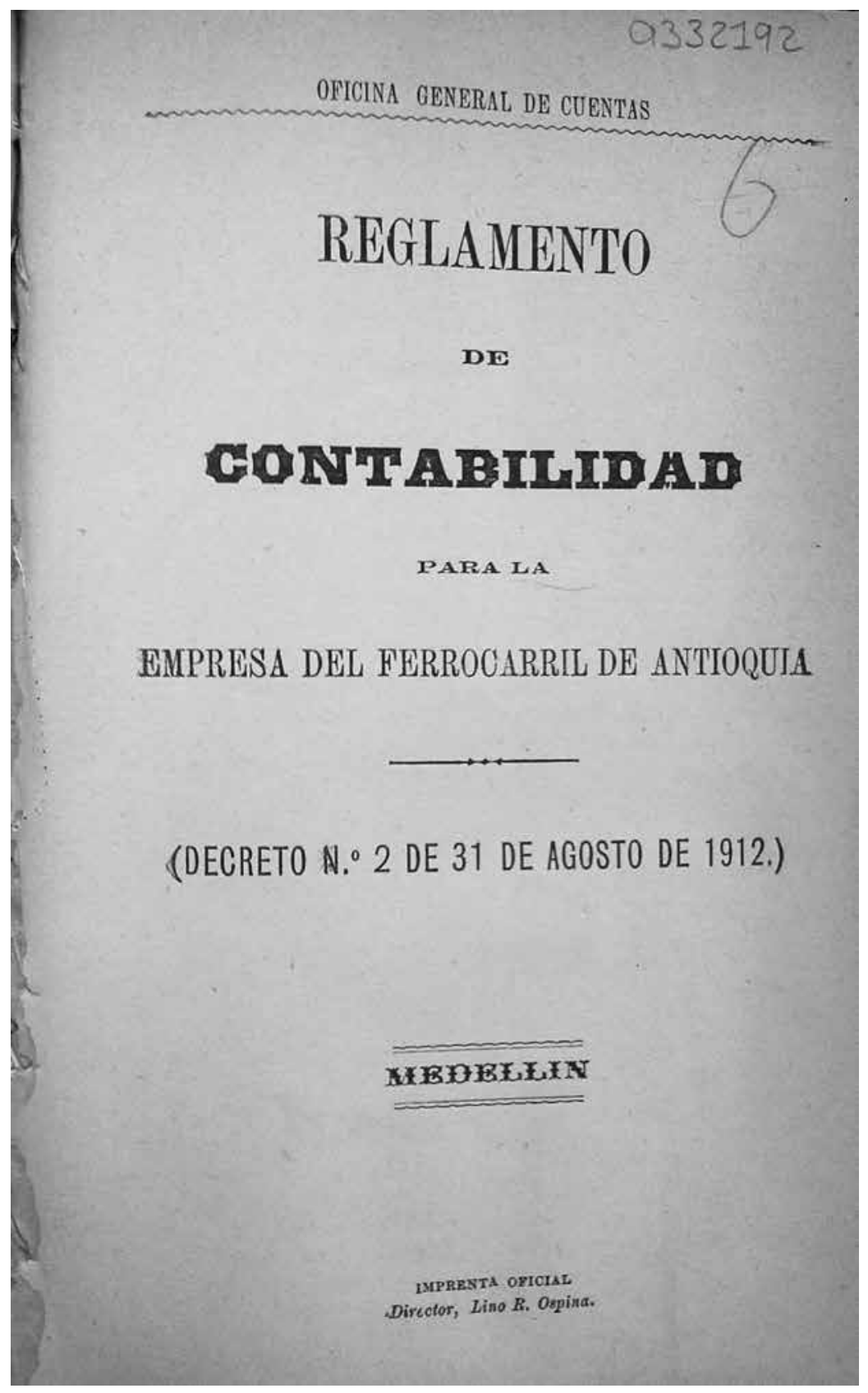

Figura 4

Carátula del reglamento de la contabilidad para el Ferrocarril de Antioquia (1912)

Fuente: Antioquia, Oficina General de Cuentas (1912, p. 1) 
En fin, de acuerdo con la regulación contable citada, en los ferrocarriles públicos, el principal usuario era, obviamente, el gobierno; y el objeto primordial era revelar datos sobre la aplicación de los recursos (gastos) y los correspondientes ingresos. No había preocupación por la cuenta de capital, y si bien se tenía implementado el sistema de la partida doble, aún dominaban las partidas simples (manifiestas en la teneduría de cuentas corrientes con proveedores) orientadas a establecer el flujo de caja como reporte básico.

La divulgación de las cifras contables, si se presentaba, se realizaba con una periodicidad poco uniforme, a veces, semestral o trimestral en las gacetas oficiales. Su gestión recaía tanto en la gerencia de la entidad como en el agente gubernamental encargado del control y la vigilancia administrativa, llámese visitador fiscal, ingeniero interventor o superintendente.

Por otra parte, en el caso de las empresas privadas (Cartagena, La Dorada, Girardot, por ejemplo), se privilegiaba el uso de la partida doble, que se sugería implícitamente en la legislación comercial desde la prescripción del primer Código Comercial neogranadino, que se expidió en 1853. Sin embargo, esto tenía poca incidencia en la revelación de la información, que no dejaba de ser restrictiva y sin uniformidad.

Como se puede inferir, el régimen concreto de las prácticas contables dependía de las políticas que cada ferrocarril implementara en la materia. Normalmente, en los estatutos y reglamentos quedaba descrito un parámetro global respecto de las cuentas y su revisión, que estaba asociado con las funciones y responsa- bilidades de los contadores, tenedores de cuentas y revisores fiscales. En el apartado siguiente se ubican estas características de la regulación contable de los ferrocarriles colombianos en las tradiciones y tendencias internacionales.

\section{La regulación colombiana de ferrocarriles y sus referentes internacionales}

Los ferrocarriles jugaron un rol fundamental en la expansión de la Revolución Industrial, también en el ámbito contable durante el siglo XIX y principios del XX. En este sentido, la regulación del sector y en particular de sus cuentas y reportes contables marcó una pauta considerable en el desarrollo de la gestión financiera, los costos, la auditoría y otras áreas de la disciplina y regulación contable internacional.

En Estados Unidos, la regulación contable fue una expresión cambiante de los intereses políticos y económicos de diferentes agentes interesados, que finalmente derivó en un avance de la infraestructura y las instituciones asociadas a la generación y publicación de la información financiera de las corporaciones, no solo ferroviarias, sino de la economía en general (Miranti \& Goodman, 1996; Previts \& Merino, 1998; Rico-Bonilla, 2015b).

En el caso colombiano, si bien no se presentó un impacto de envergadura, probablemente la naturaleza de la industria ferroviaria sí implicó algunas modificaciones y cuestionamientos sobre la forma y el fondo de las prácticas, regulaciones, técnicas y procedimientos que hasta aquel momento identificaban la forma de llevar la contabilidad financiera. Sin duda, uno de los 
aspectos que más dificultaron la profundización de esa transformación fue el carácter poco integrado del sistema de trenes y trayectos y el hecho de que no adquiriera una fuerte trascendencia económica nacional.

En este sentido, es notable la influencia de la tradición española y francesa de regulación tanto en el derecho comercial y contable, como en el desarrollo de la industria en sí. Es necesario especificar más este aspecto para posteriormente reseñar la tendencia a observar las directrices empleadas en Estados Unidos como el referente legal que se comenzó a aplicar precariamente desde la nacionalización de ferrocarriles en 1905 y que llegó a ser relevante entre 1920 y 1940.

\subsection{Herencia contable de tradición española y francesa}

Como en el caso de la regulación general de cuentas, la legislación colombiana sobre ferrocarriles tenía como referencia la normatividad expedida en España y Francia; el modelo de concesiones ferroviarias que se buscó implementar por medio de la Ley 104 de 1892 reproducía los parámetros que sobre esta materia rigieron en esos dos países (Fischer, 2001; Ortega, 1920; Pachón \& Ramírez, 2006).

En ellos también la escasez de capital público requirió la formulación de un conjunto de incentivos y subvenciones para inversionistas privados, nacionales y extranjeros; en algunas ocasiones, utilizaron estos recursos en su beneficio propio más que en el desarrollo de la infraestructura al que se comprometieron (Tortella, 1995).
De forma similar, en Colombia, país heredero de esta tradición de derecho, no se produjo una regulación específica sobre la contabilidad ferroviaria privada. La tendencia fue emplear las mismas reglas sobre libros y balances que se establecieron en los Códigos de Comercio y sus correspondientes reformas (Rico-Bonilla, 2015b).

Con el tiempo, y en la medida en que una mejor situación financiera del país lo permitió, en el siglo XX, también se adoptó la política de nacionalizar líneas y trazados, para acomodar su contabilidad a los preceptos de los reglamentos públicos. Esta tendencia se manifestó plenamente con la formación del Consejo Administrativo de los Ferrocarriles Nacionales (1922), una entidad gubernamental encargada de centralizar la gestión y la información financiera de la mayoría de los trazados ferroviarios (Pachón \& Ramírez, 2006).

Del esquema de regulación continental europeo, Colombia adoptó prácticas contables como la revelación sobre actividades subyacentes a la industria ferroviaria como la explotación de minas de carbón, hospitales, telégrafos y caminos, entre otros. Sin embargo, no se aplicaron otras como el uso de reglamentos gubernamentales detallados y la publicación periódica de informes. En esta medida, temas como la uniformidad de las cuentas y el uso del valor histórico presentaron poca relevancia.

Tampoco se llegó a formular un esquema de control corporativo permanente y especializado, el país no contaba con la institucionalidad y los medios económicos para llevar a cabo esta labor. Luego, siguió un esquema de supervisión, por intermedio de comisionados y superintendentes, pero como sucedía en Europa 
Continental, en muchos casos estos funcionarios carecían de formación en contabilidad y su trabajo se limitaba a escuetas visitas que generaban poco valor a la hora de sugerir cambios en los procesos y políticas contables de las empresas.

En Colombia, la extensión de la industria ferroviaria no influyó determinantemente en el desarrollo de los mercados de auditoría externa. En esta área, la adopción de las prácticas anglosajonas fue tenue y tardía, como se enuncia enseguida.

\subsection{Tendencia a adoptar reglas contables estadounidenses}

La consolidación, en las primeras décadas del siglo XX, del espectacular crecimiento económico de Estados Unidos, sustentado en la comunicación y los ferrocarriles, ubicaron este país como un ejemplo en materia de regulación financiera y contable, incluso para los gestores, inversionistas y legisladores colombianos.

La aplicación en el país de figuras de derecho comercial anglosajón, en las que se apreciaba la diferenciación entre propiedad y gerencia, le abrió paso a cierta modernización corporativa y, por ende, contable. Por ejemplo, el fortalecimiento de las sociedades anónimas influyó en la utilización de esquemas de gobierno empresarial, en los que la asamblea de socios se diferenciaba de la junta directiva y se produjeron burocracias organizacionales más especializadas. Igualmente, las estructuras por departamentos, unidades de negocio y jerarquías que adoptaron la mayoría de los ferrocarriles colombianos eran transferencias de los modelos estadounidenses e ingleses que llegaron al país por intermedio de ingenieros y contadores que prestaron sus servicios en concesionarios con capital extranjero (Means, 2011; Mejía, 1987; Rico-Bonilla, 2015a).

El ejemplo más notable fue el de Francisco Javier Cisneros, el célebre ingeniero cubano, con nacionalidad y educación estadounidense; y sus empresas y contratos de los ferrocarriles en Antioquia, Girardot, Cauca, entre otros, fueron modelos en materia de gestión y contabilidad. De hecho, su libro Reglamentos para la organización de los trabajos de construcción y del servicio de explotación de ferrocarriles (1884) se reconoce como uno de los primeros y más influyentes sobre la disciplina de la administración de empresas en Colombia (Horna, 2003; Mayor-Mora, 1999). Uno de los aspectos en que hace énfasis es en el papel central de la contabilidad ferroviaria:

La contaduría, garantía general de las operaciones y reguladora de la marcha de la empresa, es motor de luz para todos los ámbitos de la misma y guía del Director. Peca por deficiencia el sistema que no revela en un momento dado la situación, los gastos y el esfuerzo mecánico de cada sección (Cisneros, 1884, p. 5).

En el campo de la regulación, estas ideas cobraron relevancia concreta cuando en la reglamentación local se tomó nota directa de los principios y reglas emitidas por la Interstate Commerce Commission (ICC) de Estados Unidos, y su forma de intervenir en las empresas mediante la definición de las tarifas y los conceptos fundamentales de la contabilidad financiera. La ya citada Resolución del Ministe- 
rio de Obras Públicas, sobre la contabilidad de los ferrocarriles nacionales, disponía:

4. La clasificación de los gastos de explotación, construcción o reconstrucción, en los mencionados ferrocarriles, se hará de acuerdo con las especificaciones de las cartillas publicadas por la Comisión de Comercio Interior, de los Estados Unidos, para lo cual se llevarán los correspondientes libros auxiliares (Ministerio de Obras Públicas, Resolución 31 de 1920).

De hecho, se tiene noticia de que los ferrocarriles de Antioquia, el Pacífico y la Sabana también buscaron adoptar en su contabilidad estos requerimientos estadounidenses con relativo éxito (Asamblea del Departamento de Cundinamarca, 1919). Para la década de 1920, ya se podían apreciar algunos balances generales y cuentas de resultados de ferrocarriles, presentados de acuerdo con estos preceptos anglosajones (Ministerio de Obras Públicas y Fomento, 1924).

\section{Conclusiones}

El último cuarto del siglo XIX y las primeras décadas del XX marcaron una importante época de transición en el desarrollo de las prácticas de contabilidad financiera en Colombia. Se ha ejemplificado esta situación, con un análisis de la reglamentación sobre el tema en la industria ferroviaria.

Como se ha descrito a lo largo del texto, a pesar de que los cambios fueron muy limitados, se aprecia el tránsito de un esquema de contabilidad financiera centrado en el registro de los flujos monetarios, la teneduría de libros y la gestión de la caja, a uno que poco a poco tenía más en cuenta el reconocimiento del fondo económico de las transacciones y la formación de unos reportes más idóneos para reflejar la situación financiera y la rentabilidad de las entidades ferroviarias.

En el caso de Colombia se determinó que siguiendo la tradición del derecho continental europeo, se aplicó un esquema de financiación y vigilancia de la industria similar al de España y Francia, con la puesta en marcha de un conjunto de reglamentaciones generales sobre las concesiones ferroviarias y su contabilidad.

Sin embargo, a este esquema le fueron adhiriendo políticas de intervención similares a las establecidas en Estados Unidos; incluso, se adoptaron lineamientos de la ICC, infortunadamente con menos efectividad y una infraestructura de control mucho menos desarrollada en términos de personal capacitado y conocimiento técnico.

La inestabilidad política que generaban las guerras civiles y, en especial, las restricciones en materia de política monetaria y fiscal disminuyeron la formación de capital de trabajo local e impactaron negativamente en la inversión extranjera directa. La infraestructura de ferrocarriles lograda en el país fue insuficiente, fragmentada y de baja calidad técnica. En cambio, sí se produjeron innumerables disputas legales por derechos y responsabilidades mal definidos que de plano les eran favorables a los capitalistas y profundizaban los problemas de endeudamiento del gobierno colombiano.

La información financiera que publicaban las compañías ferroviarias sobre la continuidad 
de las actividades era muy escasa, a pesar de que estas entidades recibían tanto dineros públicos como de algunos inversionistas locales y foráneos. Esta situación no se diferenciaba mucho en los ferrocarriles estatales, que se caracterizaban más, desde el punto de vista contable, por reconocer y elaborar la información siguiendo un esquema de contabilidad más propio de la recaudación y el empleo de fondos de las tesorerías gubernamentales.

Se observó un esquema en el que el concesionario privado de ferrocarriles tenía la libertad de definir sus políticas contables atendiendo a los intereses de los capitalistas propietarios, sin un parámetro estatal específico de estandarización o divulgación de la información financiera, más allá del que regía en la codificación general del comercio terrestre sobre libros de cuentas, auxiliares y balances.

No se produjo una reglamentación particular y sistemática de la contabilidad de las concesiones que contribuyera al desarrollo de la industria ferroviaria colombiana. El gobierno se comprometió con subvenciones y beneficios, pero no procuró asegurar los parámetros de información financiera, estadística y rendición de cuentas que le permitieran verificar el cumplimiento de las obligaciones contractuales de las empresas.

No obstante el leve fortalecimiento de la figura de la sociedad anónima, la organización moderna de las entidades económicas en estructuras piramidales definidas y especializadas, el gobierno de las sociedades con el modelo de junta de accionistas, juntas y consejos directivos o la revisoría fiscal se vieron fortalecidos por la implementación de la industria y los proyectos ferroviarios, como se ha mencionado.
La contabilidad de las sociedades anónimas, entre ellas los ferrocarriles, influyó en que el dominio de los extractos de caja cediera terreno a los balances de explotación y a los estados de la situación financiera, y finalmente la regulación avanzó en la parametrización de estas materias en Colombia.

\section{Referencias}

Anzola, Nicasio (1926). Curso elemental de derecho mercantil. Bogotá: Imprenta de la Luz.

Arias de Greiff, Gustavo (1986). La mula de hierro. Bogotá: Carlos Valencia Editores.

Ariza-Buenaventura, Efrén Danilo (2001).

El carácter de la empresa y la contabilidad en la Nueva Granada (tesis de maestría en sociología industrial sin publicar). Universidad Nacional de Colombia, Bogotá. Disponible en: http://s35e52fba07274b91. jimcontent.com/download/ version/1330471096/module/3580789154/ name/Danilo+Ariza +Tesis + de+Maestria pdf

Asamblea del Departamento de Cundinamarca (1919). Informe de la comisión que visitó la Empresa del Ferrocarril de la Sabana y los trabajos de prolongación al bajo Magdalena. Bogotá: Imprenta del Departamento.

Baskin, Jonathan Barron \& Miranti, Paul J. (1999). A History of Corporate Finance. New York: Cambridge University Press.

Bernal-Gutiérrez, Rafael (1991). El Código de Comercio colombiano (historia $y$ proyecciones). En Instituto de Investigaciones Jurídicas (eds.). Centenario del Código de Comercio, 85-108. Ciudad de México: Universidad Nacional Autónoma 


\section{HISTORIA DE LA REGULACIÓN CONTABLE FINANCIERA EN COLOMBIA / C. RICO / 69}

de México, UNAM. Disponible en: http:// bibliohistorico.juridicas.unam.mx/ libros/2/640/6.pdf, http://bibliohistorico. juridicas.unam.mx/libros/libro.htm?l=640 Bernal-Lloréns, Mercedes (1998). En torno a la regulación contable en el Código de Comercio de 1829. Revista Española de Financiación y Contabilidad, REFC, 27 (97), 887-912. Disponible en: http://aeca.es/old/refc_19722013/1998/97-1.pdf

Berti, José Agustín (1901). Ferrocarril de Cúcuta: informe del presidente a los accionistas. Cúcuta: Tipografía de M. Lascano e Hijo.

Cardona-Arteaga, John (1987). La contabilidad a través del derecho comercial colombiano. Revista Contaduría, Universidad de Antioquia, 11, 17-42. Disponible en: http:// aprendeenlinea.udea.edu.co/revistas/index. php/cont/article/view/24988/20312

Chandler, Alfred D. (1987). La mano visible. La revolución en la dirección de la empresa norteamericana. Madrid: Ministerio de Trabajo y Seguridad Social.

Chandler, Alfred D. (1996). Escala y diversificación: la dinámica del capitalismo industrial. Zaragoza: Editorial Prensas Universitarias de Zaragoza.

Cisneros, Francisco Javier (1884). Reglamentos para la organización de los trabajos de construcción y del servicio de explotación de ferrocarriles. Bogotá: Imprenta de la Luz.

Correa-R., Juan Santiago (2012). The Panama Railroad Company o cómo Colombia perdió una nación. Bogotá: Editorial del Colegio de Estudios Superiores en Administración, CESA.
Fischer, Thomas (2001). El comienzo de la construcción de los ferrocarriles colombianos y los límites de la inversión extranjera. Bogotá: Universidad de los Andes, Monografías de la Administración, 60.

González, H. (1958). De los libros de comercio. Cali: Imprenta Departamental.

Horna, Hernán (2003). Los ferrocarriles latinoamericanos del siglo XIX: el caso de Colombia. En Carlos Dávila-Ladrón de Guevara (comp.). Empresas y empresarios en la historia de Colombia, siglos XIX-XX, 1021-1044. Bogotá: Grupo Editorial Norma, Comisión Económica para América Latina y el Caribe, CEPAL, Universidad de los Andes. Disponible en: http://repositorio. cepal.org/handle/11362/1780

Junguito, Andrea (1997). Historia económica del Ferrocarril del Norte. Historia Crítica, 14, 129-146. Disponible en: https:// historiacritica.uniandes.edu.co/datos/pdf/ descargar.php?f=./data/H_Critica_14/09_ espa_estudi_H_Critica_14.pdf.

Machado-Rivera, Marco Antonio (2006). Una aproximación histórica a las representaciones contables en Colombia. De Computis - Revista Española de Historia de la Contabilidad, 5, 166-192. Disponible en: http://www.decomputis.org/dc/articulos_ doctrinales/machado_rivera5.pdf

Mariño-Pinto, Enrique (1927). Código de ferrocarriles de Colombia. Bogotá: Editorial Minerva. Mayor-Mora, Alberto (1984). Ética, trabajo y productividad en Antioquia: una interpretación sociológica sobre la influencia de la Escuela Nacional de Minas en la vida, costumbres 
e industrialización regionales. Bogotá: Ediciones Tercer Mundo.

Mayor-Mora, Alberto (1999). Francisco Javier Cisneros y el inicio de las comunicaciones modernas en Colombia. Bogotá: Banco de la República, El Áncora Editores.

McGreevey, William Paul (1975). Historia económica de Colombia, 1845-1930. Bogotá: Ediciones Tercer Mundo.

Means, Robert Charles (2010). Desarrollo y subdesarrollo del derecho. Corporaciones y derecho corporativo en la Colombia del siglo XIX. Alberto Supelano (trad.). Bogotá: Universidad Externado de Colombia.

Mejía, C. (1987). La nación y los ferrocarriles: auge y deterioro. Bogotá: Universidad Nacional de Colombia.

Ministerio de Obras Públicas y Fomento (1924). Inventarios de los ferrocarriles de Propiedad Nacional en 31 de diciembre de 1923. Revista del Ministerio de Obras Públicas y Fomento, 1 (6-10), 376A-376C.

Miranti, Paul J. \& Goodman, Leonard (1996). Railroad Accounting (US). En Michael Chatfield \& Richard Vangermeersch (eds.). The History of Accounting - An International Encyclopedia, 487-491. New York: Garland Publishing Inc.

Ortega, Alfredo (1920). Ferrocarriles colombianos. Resumen histórico. Bogotá: Imprenta Nacional.

Ospina-Vásquez, Luis (1987). Industria y protección en Colombia 1810-1930. Medellín: Biblioteca Colombiana de Ciencias Sociales, Fundación Antioqueña para los Estudios Sociales, FAES.
Pachón, Álvaro \& Ramírez, María Teresa (2006). La infraestructura de transporte en Colombia durante el siglo XX. Bogotá: Banco de la República, Fondo de Cultura Económica, FCE.

Palacios, Marco (2009). El café en Colombia (1850-1970): una historia económica, social y política. México: El Colegio de México.

Pérez-Ángel, Gustavo (2008). Nos dejó el tren: la historia de los ferrocarriles colombianos y el subdesarrollo. Bogotá: Ediciones Cisnecolor. Disponible en : http://www.ellibrototal. com/ltotal/?t=1\&d=4888_4921_1_1_4888

Previts, Gary John \& Merino, Barbara D. (1998). A History of Accountancy in the United States: The Cultural Significance of Accounting. Columbus: Ohio State University Press.

Pulgarín-Giraldo, Hernán \& Cano, Jairo Alberto (2000). Historia de la contabilidad pública en Colombia. Revista Contaduría, Universidad de Antioquia, 37, 87-125. Disponible en: https://aprendeenlinea.udea. edu.co/revistas/index.php/cont/article/ view/25575/21120

Rico-Bonilla, Carlos Orlando (2010). Confiscación de bienes eclesiásticos en Colombia. La contabilidad de la Agencia General de Bienes Desamortizados (18611888). De Computis - Revista Española de Historia de la Contabilidad, 7 (12), 41-83. Disponible en: https://dialnet.unirioja.es/ servlet/articulo?codigo $=3714013$

Rico-Bonilla, Carlos Orlando (2012). Historia de la contabilidad bancaria en Colombia: el caso del Banco Nacional (1880-1896). Revista Internacional Legis de Contabilidad y Auditoría, 51, 101-137. 
Rico-Bonilla, Carlos Orlando (2015a). Análisis histórico de las prácticas de contabilidad financiera del Ferrocarril de la Sabana, Colombia (1881-1917). De Computis - Revista Española de Historia de la Contabilidad, 22, 81-119. Disponible en: http://www. decomputis.org/dc/articulos_doctrinales/ rico22.pdf

Rico-Bonilla, Carlos Orlando (2015b). La historia de la contabilidad financiera en los ferrocarriles: revisión de la literatura, 1830-1910. Contabilidad y Auditoría Investigaciones en Teoría Contable, 21 (41), 87-138. Disponible en: http://ojs.econ. uba.ar/ojs/index.php/Contyaudit/article/ view/799/1480

Ridley, William (1874). Informe presentado a la Compañía Constructora de Obras Públicas de Londres. Bogotá: Imprenta de la América. Ripoll de Lemaitre, María Teresa (2000). Redes familiares y el comercio en Cartagena: el caso de Rafael del Castillo \& Co., 18611960. Cuadernos de Historia Económica y Empresarial, 5, 1-59. Disponible en: http:// www.banrep.gov.co/sites/default/files/ publicaciones/archivos/chee_5.pdf

Rippy, Fred (1977). Los comienzos de la era ferroviaria en Colombia. En Jesús Bejarano (ed.). El siglo XIX en Colombia visto por historiadores norteamericanos, 221-243. Bogotá: Editorial La Carreta.

Safford, Frank (2010). El problema de los transportes en Colombia en el siglo XIX. En Adolfo Meisel-Roca \& María Teresa Ramírez (eds.). Economía colombiana del siglo XIX, 523-573. Bogotá: Fondo de Cultura Económica, FCE, Banco de la República.
Salgar, J. (1877). Memoria del Secretario de Hacienda y Fomento dirigida al presidente de los Estados Unidos de Colombia para el Congreso de 1877. Bogotá: Imprenta de Gaitán. Disponible en: http://www.banrep. gov.co/sites/default/files/memorias_ hacienda/1877-MEMORIAS_DE_ HACIENDA_Y_FOMENTO-Parte1.pdf Sierra-González, Ernesto María (2001). Evolución de la normativa contable en Colombia. INNOVAR - Revista de Ciencias Administrativas y Sociales, 17, 47-65. Disponible en: http://www.bdigital.unal.edu. co/26615/1/24230-84853-1-PB.pdf

Tortella, Gabriel (1995). Los orígenes del capitalismo en España: banca, industria y ferrocarriles en el siglo XIX. Madrid: Tecnos.

Uribe, Antonio José (1907). Derecho mercantil colombiano. Berlín: Decker's Verlag.

\section{Legislación}

Antioquia, Oficina General de Cuentas (1912). Reglamento de la Contabilidad para la Empresa del Ferrocarril de Antioquia.

Colombia (1904). Decreto 1036 de 1904, 27 de diciembre, sobre contabilidad de la hacienda nacional.

Colombia (1887). Ley 57 de 1887, 15 de abril, sobre adopción de códigos y unificación de la legislación nacional. Disponible en: http://www.javeriana.edu.co/personales/ hbermude/leycontable/contadores/1887ley-57.pdf

Colombia (1888). Ley 27 de 1888, 21 de febrero, que reforma el Código de Comercio. Disponible en: http://www.javeriana. 
edu.co/personales/hbermude/leycontable/ contadores/1888-ley-27.pdf

Colombia (1892). Ley 104 de 1892, 26 de diciembre, sobre ferrocarriles. Disponible en: http://www.suin-juriscol.gov.co/ viewDocument.asp?id=1639179

Colombia (1896). Ley 61 de 1896, 3 de noviembre, por la cual se adiciona la ley 104 de 1892, sobre ferrocarriles. Disponible en: http://www.suin-juriscol.gov.co/ viewDocument.asp?id=1614346

Colombia (1905). Ley 20 de 1905, 14 de abril, por la cual se dictan varias disposiciones fiscales y de contabilidad oficial y mercantil. Disponible en: http://www.suin-juriscol. gov.co/viewDocument.asp?id=1575715

Colombia (1905). Ley 27 de 1905, por la cual se concede una autorización al Poder Ejecutivo.

Colombia (1915). Decreto 1115 de 1915, sobre administración de los ferrocarriles de propiedad nacional.

Colombia, Ministerio de Obras Públicas (1920). Resolución 16 de 1920, por la cual se aprueba el reglamento que organiza la inspección e intervención del gobierno sobre las empresas de ferrocarriles.

Colombia, Ministerio de Obras Públicas (1920). Resolución 31 de 1920, por la cual se reglamenta la contabilidad oficial de los ferrocarriles nacionales.

España (1829). Código de Comercio, Real Orden de 30 de mayo de 1829. Disponible en: http://fama2.us.es/fde/ocr/2006/ codigoDeComercio1829.pdf
Estado de Antioquia, Tribunal Superior (1875). Informe a la Legislatura 1875.

Estado de Panamá (1869). Código de Comercio, 12 de octubre de 1869.

Estados Unidos de Colombia (1863). Constitución Política 1 o Constitución de Rionegro, Rionegro, 8 de mayo de 1863. Disponible en: http://www.alcaldiabogota.gov.co/sisjur/ normas/Norma1.jsp?i=13698

Estados Unidos de Colombia (1871). Ley 69 de 1871, 6 de junio, sobre fomento de varias mejoras materiales y colonización de tierras baldías.

Estados Unidos de Colombia (1873). Ley 106 de 1873, 13 de junio, Código fiscal.

Nueva Granada, Congreso Constitucional (1853). Ley 2193 de 1853, 1 de junio, Código de Comercio. Disponible en: http://www. javeriana.edu.co/personales/hbermude/ leycontable/contadores/1853-ley-2193.pdf

- Fecha de recepción: 14 de julio de 2015

- Fecha de aceptación: 14 de marzo de 2016

- Disponible en línea: 15 de mayo de 2016

\section{Para citar este artículo}

Rico-Bonilla, Carlos Orlando (2016). Historia de la regulación contable financiera en Colombia. El caso de la industria ferroviaria (1870-1920). Cuadernos de Contabilidad, 17 (43), 43-72. http://dx.doi. org/10.11144/Javeriana.cc17-43.hrcf 